\title{
OS REPUBLICANOS DE 1870 E AS REALIDADES NACIONAIS.
}

\author{
RAUL DE ANDRADA E SILVA \\ Do Departamento de História da Faculaade de Filo- \\ sofia, Letras e Clênclas Humanas da Universidade de \\ Sto Paulo.
}

Cuidadosamente redigido e muito bem escrito, pelos moldes do estilo do tempo, o Manifesto republicano, de 3 de dezembro de 1870, denota a extrema acuidade dos seus autores para escutar os primeiros estalidos e distingüir as brechas, que já começavam a comprometer a estabilidade do edifício imperial, percebendo a oportunidade propícia à divulgação daquele documento. Era menos uma proclamação partidária que uma análise do sistema político barsileiro e da prática do mesmo, quase sem tocar nas realidades sócio-econômicas do momento. Mesmo politicamente, seu texto carece de conteúdo republicano mais definido, mais amplo, faltando-lhe sobretudo entusiasmo, essa vibração sem a qual os documentos de tal natureza não chegam a emocionar o público, nem a produzir efeitos imediatos.

Realmente, o Manifesto passou, sem que provocasse uma arregimentação decisiva de fôrças, dispersando-se os seus signatários, alguns dos quais até voltaram a servir à Monarquia. Quem eram êles?

A maioria dos nomes vêm acompanhados da qualificação ou da atividade profissional de cada um, havendo entre êles quinze advogados, três dos quais em ação no jornalismo, cinco jornalistas, nove médicos, cinco engenheiros, sete negociantes, dois professôres, três empregados públicos, um fazendeiro, um capitalista, além de uns poucos mais, que se limitaram a assinar. Não aparecem militares a quem caberia o papel de fôrça executora, na queda da Monarquia. E não chegavam a seis dezenas. Alguns dêsses nomes, próceres da primeira hora, ficaram na vanguarda dos chamados "republicanos históricos": Quintino Bocayuva, Saldanha Marinho, Aristides Lobo, Francisco Rangel Pestana, Salvador de Mendonça, Lopes Trovão.

Pela condição social e pelo pendor político, vê-se que tais adeptos do nôvo credo emergiam quase exclusivamente dos setores médios da sociedade, setores que se vinham constituindo entre o tôpo da escala, ocupado pela velha aristocracia agrária, e os degraus inferiores, reservados à mão-de-obra servil. Não representavam êles a rigor 
"uma classe" média ou média burguesia, dotada de coerência, mentalidade, hábitos e comportamento, que possibilitem sua caracterização como classe social (1). Mas, traduziam os anseios políticos dos espíritos que sentiam a incapacidade do regime imperial para ajustar-se às transformações que, malgrado as resistências do conservantismo, sucediam-se gradativamente. Mudança paulatina, mas inevitável, dos quadros sociais, sob o influxo da modernização do siste$\mathrm{ma}$ econômico, que decorria do aparecimento de novas modalidades e técnicas da produção: a introdução ainda tímida, mas promissora, dos primeiros mecanismos nos engenhos de açúcar e nas indústrias incipientes; a construção das primeiras ferrovias, a instalação do telégrafo, o aumento da navegação a vapor, no setor dos transportes e comunicações; a ampliação do comércio exterior, ao lado do alargamento do mercado interno e das atividades bancárias, tudo sob o vigoroso impulso comunicado a êsses empreendimentos pelo extraotdinário surto do café, que por 1870 já ascendera a quase $50 \%$ do valor das exportações brasileiras e ensejava a disponibilidade de capitais indispensáveis. Sem possibilidades de acesso à propriedade da terra, pràticamente monopolizada pela velha aristocracia latifundiária, os indivíduos de situação social média voltaram-se para as ocupações que a renovação econômica lhes propiciava: as profissões liberais e o comércio, além das oportunidades de ingresso no Exército, no Clero, no funcionalismo público e mesmo no Parlamento imperial e nas Assembléias legislativas provinciais. Essas aberturas alargavam progressivamente a área de expansão das camadas sociais médias, cujos interêsses, mentalidade e comportamento tendiam a distanciá-las cada vez mais do regime monárquico.

Em duas idéias políticas, essencialmente, resume-se o conteúdo do Manifesto: a condenação do Poder Moderador, vicío que gerava todos os males do govêrno, e a exaltação do princípio federativo, que corrigiria êsses males, dentro da armadura do Estado republicano. De que fontes de inspiração promanariam tais idéias?

O libelo contra o Poder Moderador estriba-se menos em considerações doutrinárias que nas acusações de eminentes monarquistas. Bem entendido, os autores do Manifesto não titubeavam em repudiar êsse instituto jurídico, mas reforçaram a própria conviç̧ão com o parecer dos adeptos do trono que igualmente o contestavam. Entre êles, alguns dos mais expressivos políticos do tempo: Eusébio de

(1). - Com efeito, náo se distingue claramente, por 1870, e năo se distingutrá pelo século XIX adiante, semelhante classe. Há, isto sim, uma setorizaçāo ou compartimentaçío entre os diferentes agrupamentos que se foram constituindo, nas zonas intermediárlas do todo social, ao longo do processo de transformação por que ia passando a socledade imperial, durante a segunda metade do século passado. Veja-se a propósito, o excelente estudo da Profa. Nicla Villela Luz: O Papel das Classes Médias Brasileiras no Movimento Republicano, in (Revista de História no $57, \mathrm{p}$. 13-14, Sáo Paulo, 1964). 
Queiroz, Nabuco de Araújo, Pinto de Campos, Francisco Otaviano e outros mais (2).

Depois de assinalar que a centralização administrativa era a organização que mais condizia com o regime colonial, o qual tinha em mira simplesmente assegurar o predomínio metropolitano e a

$$
\text { "unidade severa do mando absoluto" (3), }
$$

são invocados os precedentes do passado, como. alegados em favor da federação, princípio cardeal da forma de govêrno que convinha substituir à Monarquia. A tendência autonômica, que o Manifesto qualifica de democrática, foi desfraldada pela Constituinte de 1823, a qual intentou concretizá-la (4). Dissolvida a Assembléia, desencadeou-se a reação centralista, que subjugou as províncias, sujeitando-as à onipotência da Corôa. Mas, a idéia, embora sufocada, não estava morta. A revolução de 7 de abril de 1831 , desferindo os primeiros golpes contra o regime estritamente unitário da Constituição de 1824, abria caminho à idéia federativa (5). E o Partido Liberal, surgido da crise da Abdicação, incluia no projeto de reforma constitucional, apresentado à Câmara, o preceito segundo o qual o Império Brasileiro seria uma Monarquia federativa, além de preconizar também a supressão do Poder Moderador (6). Do Ato Adicional, que em 1834 conferia poderes legislativos às Assembléias provinciais, até a revolução praieira, em 1848, a agitação que abalou o Império era dinamizada pelo ideal federativo, que só ficou adormecido por obra da reação monárquica, suficiente para contê-lo, em virtude do "instinto pacífico dos cidadãos", no diagnóstico do Manifesto (7).

Como então realizar a federação sem a República?Essa teria de ser a solução, na linha de pensamento do Manifesto. Mas, a fórmula republicana era igualmente sugerida por vigorosas influências exógenas. Era momentoso o exemplo francês da República de 70, exemplo revestido da fôrça persuasiva dos modelos de procedência européia, e que não tardaria a ser reproduzido em 1873, na Espanha, cujas atividades republicanas aqui também repercutiam. Não menos influentes eram as sugestões da república federativa norte-americana,

(2). - "Manifesto Republicano", em Matos (Odilon Nogueira de), Noticia Bibliográfica e Histórica, p. 12-13, Ano II, no 16, São Paulo, setembro de 1970. Boehrer (George C. A.), Da Monarquia à República, p. 214, MEC. Rio de Janeiro, s. d.

(3). - "Manlfesto Republicano", em Matos (Odilon Nogueira de), ob. cit., p. 17.

(4) . "Manifesto Republicano", em Matos' (Odilon Nogueira de), ob. cit., p. 17-18.

(5) . 一 Ibidem.

(6). - Melo (Américo Brasiliense de Almeida), Os Programas dọs Partidos e o 2. Impérto, p. 8, Săo Paulo, 1878; Boehrer (George C. A.), ob. cit., p. 23.

(7) . - "Manifesto Republicano", em Odilon Nogueira de Matos, ob. cit., p 18-19. 
aos olhos dos seus admiradores brasileiros. Para homens como Quintino Bocayuva, os Estados Unidos provavam não sòmente as virtudes do seu regime político, mas também os benefícios da prosperidade, da tranqüilidade e da segurança que aquêle regime podia proporcionar em maior grau que qualquer outra experiência no mundo civilizado (8). E também se fazia sentir o influxo da convizinhança das repúblicas platinas, com as quais a Guerra do Paraguai pôs numerosos brasileiros em contacto mais direto, principalmente a $\mathrm{Ar}$ gentina, que já vencera a crise das convulsões internas e se encaminhava para a institucionalização da República.

Cabe notar que, doutrinàriamente não há traço do Positivismo no Manifesto de 70 (9), a não ser na adoção da forma republicana. Mais afeiçoados aos princípios da liberal-democracia e do sistema representativo, os autores do Manifesto nunca pensaram na ditadura republicana dos adeptos da ortodoxia positivista. Aos prosélitos de Augusto Comte, estaria reservado papel de destaque nos desenvolvimentos ulteriores da propaganda e no desfêcho de 1889 .

O documento abre com a declaração de que é a voz de um partido político que se vai fazer ouvir. Partido cuja legitimidade decorria da Carta constitucional de 1824, que previa sua própria reforma e assim garantia a liberdade de discutir os

"inauferíveis direitos da nação" (10).

Mas, a intenção de não convulsionar a sociedade é desde logo proclamada. Esclarecer o público, debater os problemas, buscar as soluções. Em suma, a revolução moral, nos próprios têrmos do Manifesto (11).

$\mathrm{Na}$ subseqüente exposição de motivos, sustentava-se que a vida pública do Brasil mergulhara numa estagnação, contra a qual de todos os quadrantes do país erguiam-se protestos. Não interessava atribuir a pessoas o aniquilamento dos elementos democráticos do Estado. O mal residia no próprio sistema estatal, que não comportava um autêntico regime de responsabilidade, dada a hipertrofia do Poder Moderador, mola central do mecanismo político, numa Constituição que se desdobrava em cadeia de privilégios: privilégio de religião, de raça, de sabedoria, de posição. Tal em resumo a fórmula social e política do Brasil (12). Esse o diagnóstico da crise institucional, cujo processo histórico a seguir é analisado.

(8). - Viana (J. F. Oliveira), O Ocaso do Império, p. 95-96, Sáo Paulo, 1925.

(9) . - Costa (J. Cruz), Pequena História da República, p. 39, Rlo de Janelro, 1968; Viana (J. F. Ollveira), ob. cit., p. 120.

(10). - "Manifesto Republicano", em. Matos (Odilon Nogueira de), ob. cit. p. 2.

(11). - Ibtdem.

(12). - "Manifesto Republicano"; em Matos, Odllon Noguelra de, ob. cit, p. 3-5. 
Para os signatários do Manifesto, o Brasil independente nascera comprometido por um vício de origem: sobrepondo seus interêsses dinásticos às aspirações de liberdade, que animavam o movimento da Independência, $\mathrm{o}$ rei português deixou o filho como seu sucessor no trono, sem que se chamasse o povo a votar. Para acobertar o artifício da aclamação do Imperador, convocou-se uma Constituinte, que o soberano onipotente desejava submissa à sua vontade. Como reagisse, a Assembléia foi dissolvida, seus membros, dissociados, presos ou proscritos. A outorga de uma Constituição completou a obra do despotismo e consagrou o poder pessoal do monarca, que anulava os demais poderes, teòricamente constituídos. A revolução do 7 de abril trazia a perspectiva de reformas liberais, que os pró-homens da Regência intentaram realizar, mas que sé malograram por causa dos próprios vícios das instituições vigentes. O mal era orgânico. E a reação monárquica que sucedeu à Maioridade truncou, desnaturou ou revogou a legislação democratizante. Foram, pois, iludidos os anseios das revoluções de 1822 e 1831. E assim conclui êste passo do Manifesto:

"A liberdade aparente e o despotismo real, a forma dissimulando a substância, tais são as características da nossa organização constitucional" (13).

Havia mais. O monarca que se consagrara inviolável e irresponsável, estava investido de faculdades bastantes para invalidar as liberdades públicas, que a Carta outorgada simulava garantir. Era na expressão do Manifesto o "sofisma em ação", resultante do Poder Moderador, cujo exercício concentrava na pessoa do imperante tôda ação política, pois das suas decisões dependia o funcionamento dos outros órgãos do Estado: do Executivo, porque em última análise o Imperador escolhia os ministros, cujos nomes eram submetidos à sua aprovação; do' Legislativo, porque o Imperador podia dissolver a Câmara e designava os Senadores, eleitos em primeiro grau; do Judiciário, porque o Imperador nomeava, removia e aposentava os magistrados. Assim, tôdas as liberdades ficavam pràticamente nulificadas ou banidas, e a nação, sem nenhuma representação efetiva (14).

Passa o Manifesto a invocar os pareceres de abalizados homens públicos que, de uma forma ou de outra, opinaram sôbre os malefícios decorrentes do Poder Moderador e sôbre as dificuldades que o sistema constitucional criava para as relações entre o soberano e os homens de govêrno. Nêste passo, os autores do Manifesto se mostram extremamente hábeis, ao selecionar as opiniões citadas de monarquistas notórios e convictos, marcados pela fidelidade ao seu credo

(13) . - Idem, p. 5-9.

(14). - Idem, pp. 9-11. 
político (15). Impressiona, com efeito, a concordância dos testemunhos invocados: o exercício do poder pessoal, no conceito dêsses depoimentos, arruinara o sistema representativo e a responsabilidade governamental. Era uma debilidade congênita, a minar o organismo político do Império. Daí, o brado de Silveira da Mota, no Senado:

"Cheguei à conclusão de que o vício não está nos homens, está nas instituições” (16).

Quando em seguida o Manifesto passa a proclamar a legitimidade da federação, começa a repontar a defesa do regime republicano, como solução para o problema político brasileiro. Rebuscam-se as origens da federação, que a própria geografia selou, mediante as diversificações regionais. Mas, não convinha ao mercantilismo colonial e, depois, ao monarquismo centralizador dividir o país em autonomias locais. E a Independência respeitou essa tradição, que a Constituinte de 1823 tentou modificar, emprestando a máxima anplitude ao princípio federativo. Mas, foi dissolvida e em 1824 a Constituição imperial estatuiu a centralização unitária. Por isso, as rebeliões de 1824 a 1848 tiveram uma só causa: os anseios da autonomia provincial. E se a reação monárquica havia podido conter as fôrças democratizadoras, isso estava custando ao povo o despotismo, a corrupção, a nulificação da soberania nacional, a submissão dos interêsses populares aos da Corôa. Só a federação poderia assegurar a comunhão da família brasileira; e a autonomia provincial era o

"princípio cardeal e solene que inscrevemos na nossa bandeira" (17).

Onde, pois, a "verdade democrática"? Para os signatários do Manifesto, não podia estar na monarquia constitucional representativa, por ser utópica, uma vez que são antinômicos e inconciliáveis a hereditariedade do poder e a soberania nacional. Mas, na discussão do artigo 12 da Constituição de 1824, segundo o qual todos os poderes são delegados da nação, o texto do Manifesto se torna um tanto casuístico e teorizante, chegando ao extremo de jogar com a idéia da origem divina do poder dos reis, idéia de que evidentemente não há vislumbre no texto constitucional. Não há conciliação possíve], entendiam os republicanos de 70, entre poderes hereditários e representação nacional, e sem esta perece a soberania do povo. Ao findar êste passo, apontam-se as duas "violações flagrantes" da soberania, na Carta de 1824: o princípio dinástico e a vitaliciedade do Senado imperial (18).

\footnotetext{
(15). - Idem, pp. 11-16.

(16). - Idem, p. 14.

(17). - Idem, pp.16-20.

(18) . - Idem, pp. 20-24.
} 
Conclui o documento, assinalando a necessidade da convocação moral de simples oportunistas que apenas ansiavam pelo poder. Instaurar um nôvo regime. $\mathrm{E}$ só então falam os signatários do Manifesto em reformas complexas,capazes de abranger "todo o nosso mecanismo social". Mas, falam de passagem, sem esmiuçar as reformas apenas mencionadas. Arvoram a bandeira do "partido republicano federativo". E terminam sublinhando a incompatibilidade entre a monarquia brasileira e as repúblicas americanas. Era mister que se rompesse a modalidade de isolamento resultante dêsse contraste. O Brasil, por sua reforma política, devia enquadrar-se na América, e o nôvo partido seria o veículo dêsse contacto fraterno e da solidariedade continental (19).

Nos têrmos em que está vazado, o Manifesto de 70 incorreu em críticas por vêzes rigorosamente severas. Censores há que chegam a increpá-lo de vazia sonoridade (20) e, por sua carência de conteúdo doutrinário, atribuem aos seus signatários a triste situação moral de simples oportunistas que apenas ansiavam pelo poder. Outros, mais objetivos, não questionam a sinceridade daqueles republicanos, preferindo assinalar no que escreveram o divórcio entre as idéias políticas e as realidades sociais (21), ressaltando a contradição que havia em preconizar govêrno republicano e regime representativo, para uma sociedade com escravos e sem opinião pública amplamente organizada. Com efeito, a maneira de pensar dos republicanos de 70 exemplifica a "política silogística", de que falava Joaquim Nabuco (22), isto é, uma política fundamentada em teses e abstrações, em vez de atentar nos homens e nos fatos do momento; conceito que igualmente se ajustava aos idealizadores da Constituição imperial.

Se excetuarmos o repúdio da Monarquia, com a opção declarada pela República, o Manifesto nada veio acrescentar às proclamações dos monarquistas liberais, antes dêle divulgadas (23). E até se distanciou singularmente dos programas do liberalismo radical de 1868 e 1869, no tocante à emancipação dos escravos, que êstes adotavam expressamente e sôbre o qual o Manifesto prudentemente silenciava (24) . Contradição berrante, em geral explicada pelo cálculo oportunista de não afugentar a adesão dos senhores de escravos, e da qual manda a justiça que sejam isentados os reppublicanos abolicionistas, como por exemplo Saldanha Marinho, Aristides Lobo, Rangel Pestana, no Rio de Janeiro, e Américo Brasiliense, Américo

(19) . - Idem, pp. 24-25.

(20). - Santos (José Maria dos), A Politica Geral do Brasil, p. 205, Sáo Paulo. 1930.

(21). - Viana (J. F. Ollvelra), ob. cit., p. 98-99.

(22). - Nabuco (Joaquim), Balmaceda, apud Vlana, J. F. Ollvelra, ob. cit., p.98.

(23) . - Boehrer (George C. A.), ob. cit., p. 217.

(24). - Melo (Américo Brasiliense de Almeida), ob. cit., pp. 29 e 43. 
de Campos, Francisco Glycério, em São Paulo (25) . Essa preocupação em preservar o apôio de esscravocratas republicanos, êsse temor de enfrentar o problema da abolição persiste no Congresso Republicano, reunido na capital paulista, em 1873, pouco depois da famosa Convenção de Itú, do mesmo ano (26) .

Outra omissão do Manifesto: nenhuma palavra sôbre o sistema eleitoral vigente em 1870 e que era claramente pouco democrático. Em certo passo, afirmam seus signatários que, sob o Império, não podia haver representação nacional, porque não havia eleição livre (27). Adiante, proclamam que a soberania nacional só pode existir, se o parlamento fôr eleito pela participação de todos os cidadãos (28). Mas, não acusam formalmente as restrições da eleição indireta, que só viria a ser extirpada pela reforma de 1881 , nem o vício do voto censitário,ainda mantido na lei citada (29).

Por outro lado, no Manifesto nada se encontra das linhas de pensamento anti-burguês, que animam os escritos e a palavra de dois dissidentes do republicanismo "histórico": Aníbal Falcão e Silva Jardim, os quais, se defendiam a descentralização e a estrutura federativa, idéias também sustentadas pelo Manifesto, queriam uma reforma política que resguardasse os direitos dos trabalhadores, da maioria popular (30).

Era, porém, o texto dos repúblicos do Manifesto que traduzia, em sua cautelosa moderação, as tendências dominantes de uma sociedade ainda desprovida de classe média e proletariado capazes de ação política própria, na salvaguarda de seus peculiares interêsses. Pois o Brasil era uma nação onde a maioria popular não tinha expressão política e estava à margem da vida pública, submetida ao comando da minoria cultivada (31). Por isso, a República de 89 correspondenria ao predomínio da nova classe de proprietários rurais, não muito diversa da antiga aristocracia agrária, no plano dos interêsses econômicos: a "República dos fazendeiros", que consagrava o triunfo do individualismo, da livre emprêsa, da sujeição do trabalho ao capital. Com efeito, o advento da República velha năo acarretou abalo violento e repentino à estrutura sócio-econômica, vindo apenas favorecer e apressar as transformações pelas quais estava passando essa estrutura; e facilitar a ascenção dos homens de

(25). - Bantos (José Maria dos), ob. cit., p. 211-212; Boehrer (George C. A.), ob. cit., p. 217; Basbaum, (Leônclo), História Sincera da República, I, p. 338-339, 2a. ediçấ, Såo Paulo, 1962.

(26) . - Santos (José Maria dos), ob. cit., 207-209.

(27). - "Manlfesto Republicano", em Matos (Odilon Nogueira de), ob. cit., p. 10.

(28). - Idem, p. 22.

(29) . - Boehrer (George C. A.), ob. cit., p. 19.

(30). - Luz (Nicla Villela), ob. cit., p. 21-23.

(31). - Viana (J. F. Ollvelra), Contributçoes para a Biografia de D. Pedro II (Parte 1a.), em "Revista do Instituto Histórico e Geográfico Brasileiro", tomo especial, p. 798-799, Rio de Janeiro, 1925. 
média condição social, que eram os mais afeitos ao tipo de iniciativas da renovação em marcha (32).

As vaguezas do Manifesto talvez em parte procedam do fato de ser politicamente um tanto imprecisa a fase histórica em que surgiu êsse documento, quando ia tomando corpo a descrença no regime imperial, mas ainda não se generalizara a confiança nas excelências da República ou de outro sistema que pudesse substituir o arcabouço constitucional em vigor. O que deu vida aos dois últimos decênios da Monarquia não foram as motivações políticas, foi a febril agitação da campanha abolicionista, a mais popular, talvez a única verdadeiramente popular das campanhas do momento, capaz de inflamar os corações e as consciências.

Em todo caso, o Manifesto foi a primeira afirmação pública de um nôvo partido, que pouco a pouco se consolidaria. E a propaganda republicana, por êsse partido promovida, fơi-se desenrolando paulatina e constantemente, até que o desfêcho das três crises, tradicionalmente designadas como a questão servil, a questão religiosa e a questão militar, alienassem da Monarquia o apôio das fôrçàs de sustentação que a haviam mantido: a aristocracia agrária, a Igreja e o Exército (33). Pela evolução, não pela revolução, exatamente como preferiam os signatários do Manifesto de 1870 .

\footnotetext{
(32). - Cr. Dantas (San Tlago), Dois Momentos de Rui Barbosa, p. 17-18, Rlo de Janeiro, 1949; Baleeiro (Allomar), Rut, um Estadista no Ministério da Fazenda, p. 96, Rio de Janeiro, 1952.

(33). - Torres (Joåo Camllo de Olivelra), A Democracia Coroada, pp. 537-539, Rio de Janeiro, 1957.
} 